\title{
RIPASA vs Modified Alvarado Scoring System for diagnosis of Appendicitis
}

\author{
Bhusan Raj Timilsina, ${ }^{1}$ Rajiv Shah, ${ }^{1}$ Sudeep Raj KC, ${ }^{1}$ Hari Prasad Upadhyay, ${ }^{2}$ Sunita Lamsal, ${ }^{3}$ \\ Narayan Belbase, ${ }^{4}$ Sujit Kumar ${ }^{4}$ \\ ${ }^{1}$ Department of Urology, ${ }^{2}$ Department of Community Medicine, College of Medical Sciences, Bharatpur, Nepal, \\ ${ }^{3}$ Bakulahar Ratnanagar Hospital, Tandi, Chitwan, Nepal, ${ }^{4}$ Department of Gastroenterology, College of Medical \\ Sciences, Bharatpur, Nepal.
}

\begin{abstract}
Background: Acute appendicitis is the most common surgical condition presented to the emergency department. Clinical scoring systems such as the Alvarado and modified Alvarado scoring system were developed with the goal of reducing the negative appendectomy rate to $5 \%-10 \%$. In the other hand the Raja Isteri Pengiran Anak Saleha Appendicitis (RIPASA) scoring system was established in 2008 specifically for Asian population. The aim of this study was to compare the modified Alvarado with the RIPASA scoring system in the Nepalese population. Materials and Methods: This study included 125 patients who had undergone appendectomies from March of 2017 to January 2018. The sensitivity, specificity, positive predictive value (PPV), negative predictive value (NPV), diagnostic accuracy, predicted negative appendectomy and receiver operating characteristic (ROC) curve of the modified Alvarado and RIPASA scoring systems were derived using SPSS statistical software. Results: A total of 125 patients were included in this study according to our criteria. The cut-off threshold point of the modified Alvarado score was set at 7.0, which yielded a sensitivity of $68.64 \%$ and a specificity of $28.57 \%$. The PPV was $95 \%$ and the NPV was $5.12 \%$. The cut-off threshold point of the RIPASA score was set at 7.5 , which yielded $88.13 \%$ sensitivity and $28.57 \%$ specificity. The PPV was $95.41 \%$ and the NPV was $12.5 \%$. Conclusion: Based on the results of this study, the RIPASA score is a simple scoring system with better sensitivity and specificity similar to the modified Alvarado scoring system.
\end{abstract}

Keywords: acute appendicitis; Modified Alvarado Score (MASS); RIPASA score.

\section{INTRODUCTION}

The lifetime risk of appendicitis in general population is $7 \%,{ }^{1} 90 \%$ of cases occurring in children and young adults (peak 10-30 years) and up to $10 \%$ being in the elderly over 60 years. $^{2}$ Classical signs and symptoms of acute appendicitis were first reported by Fitz in 1886. Acute appendicitis (AA) is the most common acute surgical abdominal condition. The diagnosis AA is difficult and remains one of the most challenging diagnostic issue in surgery. Despite development in diagnostic imaging (ultrasonography, computed tomography) the diagnostic accuracy of AA remains poor. The risk of perforation in the elderly population is high, reaching levels up to $70 \%$ in somereports. $^{3}$

Unfortunately, acute appendicitis is still difficult to diagnose and misdiagnosis is not uncommon in the emergency department. ${ }^{4}$ Early diagnosis and prompt operative intervention is the key for successful management of acute appendicitis. However, the picture of acute appendicitis may not be classical, and in such situation, a policy of early intervention to avoid perforation may lead to high negative appendectomy rate. To prevent this, different scoring system are available now. Aim of this study was to compare two of these scoring system which has gained popularity. Modified Alvarado scoring system is widely used and accepted worldwide, and now RIPASA which is showing lots of promise in Asian population.

\section{MATERIALS AND METHODS}

A cross sectional study was conducted to compare RIPASA Score and Modified Alvarado Score in predicting Acute Appendicitis. Clinical diagnosis of AA was made and undergone emergency appendectomy after strong clinical suspicion of AA in Department of Surgery of College of Medical Science, Chitwan from March 2017 to January 2018.

Correspondence: Dr. Bhusan Raj Timilsina, Department of Urology, College of Medical Sciences, Bharatpur, Nepal. Email: bhusantimilsina827@gmail.com. Phone: 9851130744. DOI: 10.3126/jcmsn.v14i4.21633. Article received: 2018-10-11. Article accepted: 2018-11-28. 
Informed consent was obtained from all the patients. Ethical approval was obtained from COMSTH-IRC [College of Medical Science and Teaching Hospital - Institutional Review Committee]. Exclusion criteria was, when the preoperative diagnosis was appendicitis but postoperatively diagnosis was other than appendicitis.

A detailed clinical history and thorough clinical examination was done. The different parameters like age, gender, clinical features, investigations like; hemoglobin, leukocyte count, USG and other relevant investigation (as for preoperative requirement for operative procedure), operative findings, histopathology were recorded. The histopathological diagnosis was considered as the gold standard for the diagnosis of acute appendicitis.

All the patients were subjected to both scoring systems. Patients were operated if either of the scoring system was significant. In some cases, where there was strong clinical suspicion of AA but failed to score significantly on either of the scoring system, were subjected to conservative management.

Total 30 patients were initially subjected to conservative management out of which 4 patients $(13.3 \%)$ were managed conservatively and rest 26 $(86.7 \%)$ progressed to positive scoring system. Total 7 patients were negative on both scoring systems but on strong clinical suspicion, they were operated which is not included in this study.

All data was collected and entered in Windows Microsoft Excel for which statistical analysis were conducted by using statistical package for social science software (SPSS) version 16.0 for data analysis. A value of $\mathrm{p}<0.05$ was considered statistically significant. For the effective measure of accuracy of the diagnosis test area under the curve (AUC) has been used. The curve (ROC) is a key indicator to determine the ability of the test to determine the true state of the subject, finding the optimal cut off value, and comparing two alternative diagnostic tasks when each task is performed on the same subject. ROC was constructed and by using Hudden Index sensitivity and specificity was calculated.

According to Alvarado scoring system score of less than 7 was considered non-significant and greater and equal to 7.0 was considered significant. In
RIPASA Scoring system score more than 7.5 was considered significant and less than 7.5 was considered non- significant.

\section{RESULTS}

Out of 131 cases studied, from March 2017 to January 2018, patients who had strong clinical suspicion of appendicitis, were subjected to both of the scoring system and had undergone surgery, out of which 6 had other diagnosis so these 6 patients were excluded from this study. So, finally total of 125 patients were included in this study out of which 79 cases $(63.2 \%)$ were males and 46 cases $(36.8 \%)$ were female. Male to Female ratio was 1.71:1. The Age group most commonly involved was 11-20 years followed by 21-30 years. The minimum age is 5 years and maximum age is 80 years. The mean age is 28.95 and SD is 16.62 . Out of 125 patients, male has greater percentage of normal appendix $4 \%$ compared to female $1.6 \%$.

This study showed that chances of negative appendectomy is higher in male than in female. When Modified Alvarado score was analyzed for diagnosis of appendicitis then area under the curve was 0.581 and standard error was $0.080, \mathrm{P}$ value was 0.475 , CI of $95 \% 0.423$ to 0.738 . Sensitivity and specificity were calculated using Hudden Index were $68.64 \%$ and $28.57 \%$ respectively. Cut off point of this scoring system was 6.5 (Figure 1).

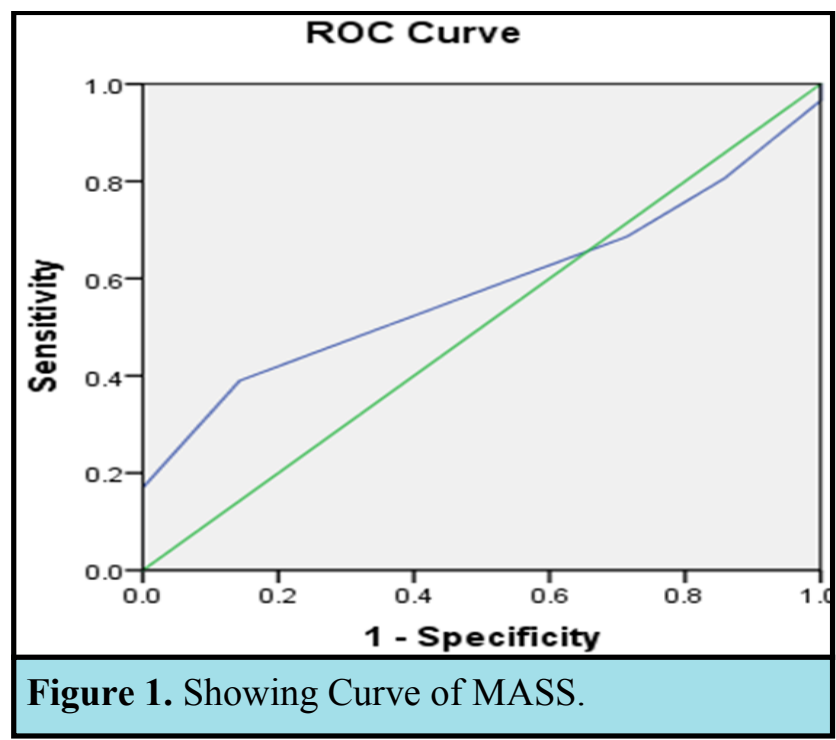

Comparing MASS with histopathology true positive was 81 , false positive was 5 , false negative was 37 and true negative was 2. Positive and negative predictive were calculated using cross tabulation method and results were $94 \%$ and $5.12 \%$ respectively with diagnostic accuracy of $66.4 \%$ (Table 1). 


\begin{tabular}{|c|c|c|c|c|}
\hline $\begin{array}{l}\text { Table } \\
\text { using }\end{array}$ & $\begin{array}{l}. \mathrm{Co} \\
\mathrm{K} 2 \mathrm{tal}\end{array}$ & irison of & SS and hist & 110 \\
\hline & & Histopatholo & of Appendix & Total \\
\hline & & $\begin{array}{l}\text { Inflamed } \\
\text { appendix }\end{array}$ & $\begin{array}{l}\text { Normal appen- } \\
\text { dix }\end{array}$ & \\
\hline MASS & $\geq 7$ & $\begin{array}{l}\text { True positive } \\
81\end{array}$ & False positive 5 & 86 \\
\hline & $<7$ & $\begin{array}{l}\text { False nega- } \\
\text { tive } 37\end{array}$ & True negative 2 & 39 \\
\hline & Total & 118 & 7 & 125 \\
\hline
\end{tabular}

When RIPASA score was analyzed the area under the cure was 0.835 and standard error was 0.051 . P value was 0.003, CI of $95 \% \quad 0.736$ to 0.934. Sensitivity and specificity were calculated using Hudden Index and the results were 88.13\% and $28.57 \%$ respectively. The cutoff point of this scoring system was 7.25 (Figure 2).

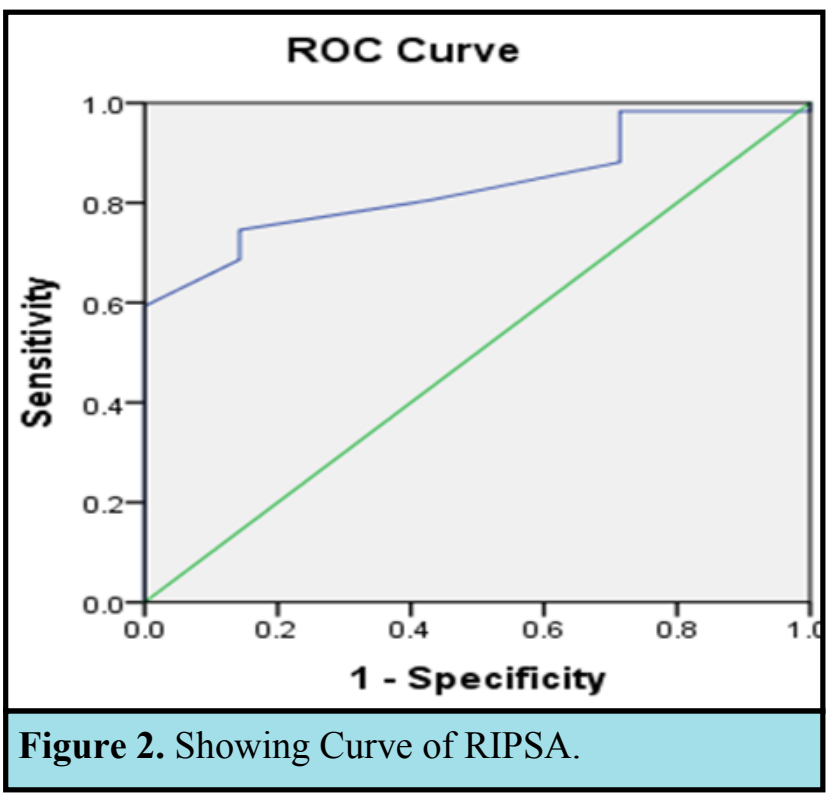

Comparing RIPASA and histopathology true positive was 104 , false positive was 5 , false negative was 14 and true negative was 2 . Positive and negative predictive were calculated using cross tabulation method and results were $95.41 \%$ and $12.5 \%$ respectively with diagnostic accuracy of $84.8 \%$ (Table 2).

\begin{tabular}{|c|c|c|c|c|}
\hline \multicolumn{5}{|c|}{$\begin{array}{l}\text { Table 2. Comparis } \\
\text { using } 2 \times 2 \text { table. }\end{array}$} \\
\hline \multirow{5}{*}{ RIPASA } & & \multicolumn{2}{|c|}{ Histopathology of Appendix } & \multirow[t]{2}{*}{ Total } \\
\hline & & $\begin{array}{l}\text { Inflamed } \\
\text { appendix }\end{array}$ & $\begin{array}{l}\text { Normal } \\
\text { appendix }\end{array}$ & \\
\hline & $\geq 7.5$ & $\begin{array}{l}\text { True positive } \\
104\end{array}$ & $\begin{array}{l}\text { False posi- } \\
\text { tive } 5\end{array}$ & 109 \\
\hline & $<7.5$ & $\begin{array}{l}\text { False negative } \\
14\end{array}$ & $\begin{array}{l}\text { True nega- } \\
\text { tive } 2\end{array}$ & 16 \\
\hline & Total & 118 & 7 & 125 \\
\hline
\end{tabular}

\section{DISCUSSION}

Diagnosis of AA is often a challenging job to the surgeon. Delayed diagnosis can lead to high morbidity and even mortality in few of the perforated peritonitis cases. To prevent complication, a high negative appendectomy 15$25 \%$ was accepted in the past. ${ }^{5,6}$ It's not that negative appendectomy is not without any complication as it increases morbidity like postoperative adhesion. ${ }^{7}$ So, diagnosis should be prompt to prevent all these complications.

There has been a lot of work to improve the diagnostic accuracy of Acute appendicitis but is still a great challenge to the treating surgeon because of different abdominal and pelvic condition that can mimic acute appendicitis, especially in children and female of patient of reproductive age.

Diagnostic accuracy can further be improved through the use of ultrasonography or computed tomography imaging. However, such routine practice may inflate the cost of health care substantially. A recent study has suggested that such indiscriminate use of CT imaging may lead to early low-grade appendicitis and unnecessary appendectomies which would otherwise be resolved spontaneously by antibiotics therapy. ${ }^{8}$

In this study Sensitivity specificity was $68.64 \%$, $28.57 \%$ respectively. Positive and negative predictive value were $94 \%$ and $5.12 \%$ respectively with diagnostic accuracy of $66.4 \%$.Nautiyal et al, in 2010 studied 50 patients with MASS Sensitivity = $40 \%$, Specificity $=93.33 \%$, Predictive value of positive test $=93.33 \%$, Predictive value of negative test $=40 \%$ and Accuracy $=56 \%{ }^{9}$ In $2008 \mathrm{R}$. Yegane et al, studied 849 patient where ROC curve analysis demonstrated increasing chance of acute appendicitis by increasing value of the modified Alvarado score $(\mathrm{P}=0.001)$, but it was neither sensitive nor specific (sensitivity, 55\%; specificity, $59 \%$ ). ${ }^{10}$ Kanumba et al, studied 127 patient the sensitivity and specificity of MASS in this study were $94.1 \%$ (males $95.8 \%$ and females $88.3 \%$ ) and $90.4 \%$ (males $92.9 \%$ and females $89.7 \%$ ) respectively. The Positive and Negative Predictive Value were $95.2 \%$ (males $95.5 \%$ and females $90.6 \%$ ) and $88.4 \%$ (males $89.3 \%$ and females $80.1 \%$ ) respectively. The accuracy of MASS was $92.9 \%$ (males $91.5 \%$ and females $87.6 \%$ ). ${ }^{11}$

In this study, RIPASA scoring had sensitivity and specificity of $88.13 \%$ and $28.57 \%$ respectively.

Positive predictive and negative predictive values 
were $95.41 \%$ and $12.5 \%$ respectively with diagnostic accuracy of $84.8 \%$. Butt et al, in 2014 studied 267 patient which showed sensitivity of $96.7 \%$ specificity of $93 \%$, Positive predictive value of $94.8 \%$ and negative predictive value of $95.54 \% .{ }^{12}$ Chong et al, detailed sensitivity $81.3 \%$, specificity $85.3 \%$, PPV $97.4 \%$ and NPV $91.8 \%$ using RIPASA score. ${ }^{13}$ Rathod et al, produce sensitivity, specificity, PPV, NPV and diagnostic accuracy of $82.61 \%, 88.89 \%, 96.61 \%, 57.14 \%$ and $83.91 \%$ respectively. ${ }^{14}$

The comparison of the modified Alvarado score and RIPASA score in our study is shown in above tables (table I and table II). Overall, the sensitivity was better with RIPASA and specificity were similar in both of the scoring system. Regarding the PPV, NPV and diagnostic accuracy, the RIPASA score was superior to the modified Alvarado scoring system. Strength of this study is it has shown that RIPASA score is more accurate to predict AA than the traditional Modified Alvarado Score.

Limitation of this study is small number of sample size and single center study. Large number of sample size and multicenter study is required to draw a more meaningful conclusion.

\section{CONCLUSION}

RIPASA score is a highly sensitive test with fair degree of specificity for the early diagnosis of acute appendicitis. With good clinical judgment, laboratory investigation and scoring systems we can decrease negative appendectomy rate. This study showed RIPASA scoring system is better than modified Alvarado scoring system.

\section{REFERENCES}

1. Chhetri PK, Tayal A, PK D. Comparison of clinical examination and ultrasonography in the diagnosis of acute appendicitis. Journal of College of Medical Sciences-Nepal. 2012;7(2):34-40.http:// dx.doi.org/10.3126/jcmsn.v7i2.6678.

2. Pokharel N, Sapkota P, Kc B, Rimal S, Thapa S, R S. Acute appendicitis in elderly patients: a challenge for surgeons. Nepal Med Coll J. 2011 Dec;13(4):2858.PMID:23016482.

3. Chang SK, P C. Recurrent Appendicitis as a Cause of Recurrent Right Iliac Fossa Pain. Singapore Med J. 2004 Jan;45(1):6-8.PMID:14976575.

4. Wei CS, Wu HP, YJ C. Routine Urinalysis in Patients with Acute Appendicitis. J Emerg Crit Care Med. $2007 ; 18$ (2):71-7. D O I :

[1 $0.1016 /$ j.annemergmed.2009.04.020].

5. Lewis FR, Holcraft JW, Boey J, JE D. Appendicitis: a critical review of diagnosis and treatment in 1,000 cases. Archives of Surgery. 1975 May;110(5):677-84.

6. Humes DJ, J S. Acute Appendicitis BMJ. 2006;333:530-4.

7. Raf L. Causes of abdominal adhesion in case of intestinal obstruction. Arta Chir Scanda. 1969;135:73 $-6$.

8. Livingston EH, Woodward WA, Sarosi GA, RW H. Disconnect between incidence of nonperforated and perforated appendicitis: implications for pathophysiology and management. Annals of surgery. $2007 \quad$ J u n ; 245 ( 6 ) : 886 -
92.DOI:10.1097/01.sla.0000256391.05233.aa

9. Nautiyal H, Ahmad S, Keshwani NK, DN A. Combined use of modified Alvarado score and USG in decreasing negative appendicectomy rate. Indian Journal of Surgery. 2010 Feb;72(1):42-8.DOI: [10.1007/s12262-010-0008-5].

10. Yegane R, Peyvandi H, Hajinasrollah E, Salehei N, $M$ A. EVALUATION OF THE MODIFIED ALVARADO SCORE. Acta Medica Iranica. 2008;46 (6):501-6.

11. Kanumba ES, Mabula JB, Rambau P, PL C. Modified Alvarado scoring system as a diagnostic tool for acute appendicitis at Bugando Medical Centre, Mwanza, Tanzania. BMC surgery. 2011 Dec;11(1):2-5.https://doi.org/10.1186/1471-2482-114.

12. Butt MQ, Chatha SS, Ghumman AQ, M F. RIPASA score: a new diagnostic score for diagnosis of acute appendicitis. J Coll Physicians Surg Pak. 2014 Dec;24(12):894-7.doi: 12.2014/JCPSP.894897.

13. Chong CF, Thien A, Mackie AJ, Tin AS, Tripathi S, Ahmad MA, et al. Comparison of RIPASA and Alvarado scores for the diagnosis of acute appendicitis. Singapore medical journal. 2011;52 (5):340-5.PMID:21633767.

14. Rathod S, Ali I, Bawa AP, Singh G, S M. Development of the RIPASA score: a new appendicitis scoring system for the diagnosis of acute appendicitis. Singapore Med J. 2010;51:220-5.

Citation: Timilsina BR, Shah R, KC SR, Upadhyay HP, Lamsal S, Belbase N, Kumar S. RIPASA vs Modified Alvarado Scoring System for Diagnosis of Appendicitis. JCMS Nepal. 2018;14(4):213-6. 